\title{
SamurAI: a 1.7MOPS-36GOPS Adaptive Versatile IoT Node with 15,000x Peak-to- Idle Power Reduction, 207ns Wake-up Time and 1.3TOPS/W ML Efficiency
}

Ivan Miro-Panades ${ }^{1}$, Benoit Tain ${ }^{2}$, Jean-Frédéric Christmann ${ }^{1}$, David Coriat ${ }^{1}$, Romain Lemaire ${ }^{1}$, Clement Jany $^{3}$, Baudouin Martineau ${ }^{3}$, Fabrice Chaix ${ }^{3}$, Anthony Quelen ${ }^{3}$, Emmanuel Pluchart ${ }^{1}$, Jean-Philippe Noel ${ }^{1}$, Reda Boumchedda ${ }^{3,4}$, Adam Makosiej ${ }^{3}$, Maxime Montoya ${ }^{3}$, Simone Bacles-Min ${ }^{1}$, David Briand ${ }^{2}$, Jean-Marc Philippe ${ }^{2}$, Alexandre Valentian ${ }^{1}$, Frédéric Heitzmann ${ }^{3}$, Edith Beigne ${ }^{3}$, Fabien Clermidy ${ }^{1}$

${ }^{1}$ Univ. Grenoble Alpes, CEA, LIST, Grenoble, France; ${ }^{2}$ Univ. Paris-Saclay, CEA, LIST, Gif sur Yvette, France; ${ }^{3}$ Univ. Grenoble Alpes, CEA, LETI, Grenoble, France; ${ }^{4}$ STMicroelectronics, Crolles, France; Email: ivan.miro-panades@cea.fr

\begin{abstract}
IoT node application requirements are torn between sporadic data-logging and energy-hungry data processing (e.g. image classification). This paper presents a versatile IoT node covering this gap in processing and energy by leveraging two on-chip sub-systems: a low power, clock-less, event-driven Always-Responsive (AR) part and an energy-efficient OnDemand (OD) part. The AR contains a 1.7MOPS event-driven, asynchronous Wake-up Controller (WuC) with 207ns wake-up time optimized for short sporadic computing. OD combines a deep-sleep RISC-V CPU and 1.3TOPS/W Machine Learning (ML) and crypto accelerators for more complex tasks. The node can perform up to $36 \mathrm{GOPS}$ while achieving $15,000 \mathrm{x}$ reduction from peak-to-idle power consumption. The interest of this versatile architecture is demonstrated with $105 \mu \mathrm{W}$ daily average power on an applicative classification scenario.
\end{abstract}

\section{Introduction}

An event-driven IoT node is a way to reduce the power consumption of sporadic computing. SamurAI (Fig. 1) combines an event-driven $\mathrm{WuC}$ using asynchronous logic (low-energy, clock-less, and fast wake-up time) in the AR subsystem with an energy efficient synchronous RISC-V CPU including specialized accelerators in the OD sub-system to make a versatile IoT node. Depending on the application needs, one or both cores can be used as shown in Fig. 2 .

\section{Always-Responsive Sub-System}

The WuC (Fig. 3), a clock-less 32b MCU [9] with 16b RISC ISA, is the master on the AR sub-system having 1.7MOPS at $0.45 \mathrm{~V}$ and $1.6 \mu \mathrm{W}$ idle power. Program and data are stored on an asynchronous $8 \mathrm{kB}$ Two-Port SRAM (TP-SRAM) [10] with auto power-down capabilities down to $0.4 \mathrm{~V}$ and $4.6 \mu \mathrm{W}$ idle power. Key component of this architecture, TP-SRAM is also connected to the OD sub-system through an AHB asynchronous interface to create a shared memory space between the two sub-systems. Thanks to asynchronous logic, the wake-up time from idle state to first instruction fetch takes $207 \mathrm{~ns}$, i.e. a third of an instruction cycle. The AR sub-system contains multiples wake-up sources: an internal timer, OD interrupts, GPIOs connected to sensors, and a Wake-up Radio (WuR). The WuR senses the radio channel with 10x less power than the main radio. Thanks to its mixerfirst topology (as in [7]) and the use of three distinct oscillators, the RF front-end enables operation in all the main IoT bands: $433 \mathrm{MHz}, 868 \mathrm{MHz}$ and $2.4 \mathrm{GHz}$. The digital baseband (DBB) supports data-rates up to $100 \mathrm{kbps}$. It decodes an $8 \mathrm{~b}$ identifier to selectively wake-up the $\mathrm{WuC}$ and a $32 \mathrm{~b}$ message payload for application specific purposes. At 50kbps data-rate, the WuR achieves $-73 \mathrm{dBm}$ sensitivity with $4.1 \mu \mathrm{W}$ power consumption at $5 \%$ duty cycle and this drop to $40 \mathrm{nW}$ in idle mode.

\section{On-Demand Sub-System}

The 4-stage pipeline RISC-V CPU is the master of the OD sub-system (Fig. 1). Its memory sub-system is composed of
$64 \mathrm{kB}$ for program (TCPM), $128 \mathrm{kB}$ for data (TCDM) and external NVM FeRAM memories. $32 \mathrm{kB}$ of TCDM have retention capability with $1.03 \mathrm{pA} / \mathrm{bit}$ leakage at $0.5 \mathrm{~V}$. An instruction cache and a data interface allow direct FeRAM operations. Both cores (in AR and OD) share the APB peripherals while synchronizing through interrupts and locks. The Crypto IP embeds AES, TRIVIUM and PRESENT stream-cipher accelerators to support various encryption formats. The adaptive voltage scaling (AVS) module manages 128 sensors (TFS) and a programmable replica path (TFR) to estimate and track the Fmax/Vmin according to the applicative needs. To offer ML inference capability in this event driven IoT node, we implement PNeuro [8] (Fig. 4), a SIMD programmable accelerator composed of 2 clusters of 32 8-bit PEs each and $264 \mathrm{kB}$ multi-banked SRAM. Designed to accelerate neural networks, it performs up to 64MACs/cycle.

\section{Measurements Results}

The $4.5 \mathrm{~mm}^{2}$ circuit (Fig. 8) has been fabricated in $28 \mathrm{~nm}$ FDSOI technology and contains 6 switchable power domains. For fair comparison with the SoA, measurements are done without using body-bias. Fig. 6 depicts Fmax and energy per cycle of the OD sub-system with RISC-V running Dhrystone, showing $19 \mathrm{pJ} / \mathrm{cycle}$ at $25 \mathrm{MHz}, 0.48 \mathrm{~V}$ and up to $350 \mathrm{MHz}$ at $0.9 \mathrm{~V}$. Fig. 7 shows the performance of PNeuro block, reaching $1.3 \mathrm{TOPS} / \mathrm{W}$ and $2.8 \mathrm{GOPS}$ at $0.48 \mathrm{~V}$ and up to $36 \mathrm{GOPS}$ at $0.9 \mathrm{~V}$ for $8 \mathrm{~b}$ precision fully-connected layers. Fig. 5 reports power consumption for different mode: $96 \mathrm{~mW}$ at full activity and $6.4 \mu \mathrm{W}$ at $0.45 \mathrm{~V}$. The $15,000 \mathrm{x}$ ratio between peak and idle power, highlights the adaptive and versatile performance of this architecture. Fig. 9 shows a scenario where SamurAI is used to classify a scene based on the presence of people signaled by a pyroelectric detector (PIR). To minimize power consumption, the $\mathrm{WuC}$ filters PIR activity based on previous scenes and powers up the OD part only when required: PNeuro classifies the images acquired by the CPU and shares results with the WuC. AES encrypted messages can be transmitted through an external low-power radio. The $\mathrm{WuR}$ is also used to receive user commands. The daily average power for this application is $105 \mu \mathrm{W}$ where $26 \%$ is consumed on SamurAI (Fig. 10). Using RISC-V instead of PNeuro would increase the total average power consumption by $2.3 x$. Fig. 11 compares the circuit to prior art and shows significant improvements in terms of versatility, performance, wake-up time and power reduction. Acknowledgments

WAKeMeUP (ECSEL 783176), SERENE-IoT (Penta 16004), MACS (FUI20) projects, ST Microelectronics, and PULP project.

\section{References}

[1] G. Lallement, JSSC, 2018. [2] Yu Pu, JSSC, 2018. [3] S. Paul, JSSC, 2017. [4] J. Myers, JSSC, 2016. [5] S. Bang, ISSCC, 2017. [6] A. Pullini, JSSC, 2019. [7] N. M. Pletcher, ISSCC, 2008. [8] A. Carbon, DATE, 2018. [9] J.-F. Christmann, JLPEA, 2019. [10] R. Boumchedda, L-SSC, 2018. 


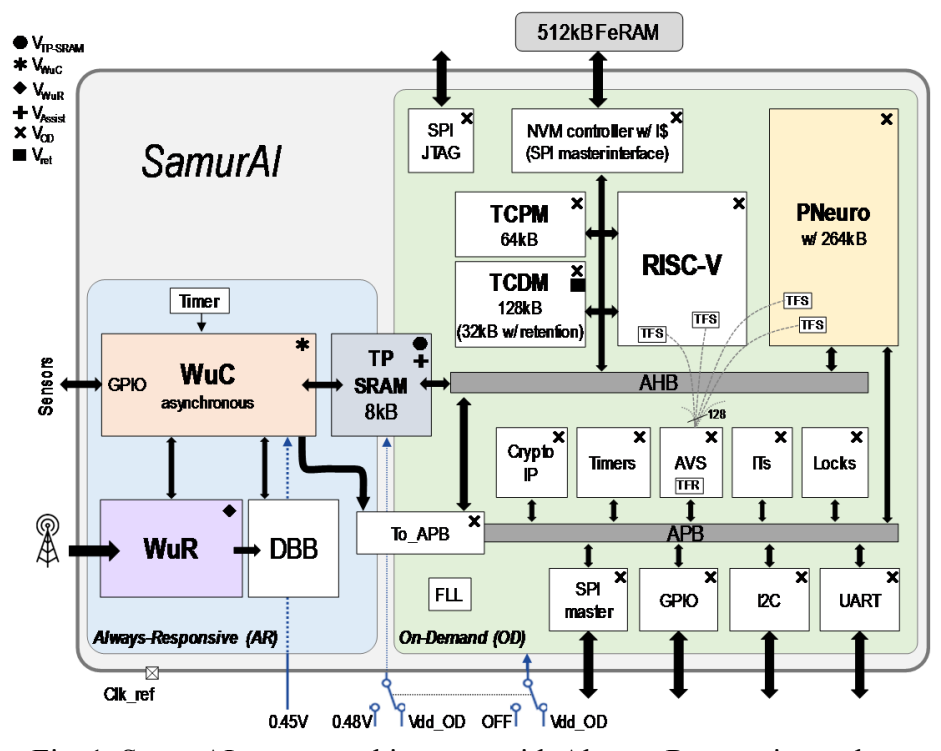

Fig. 1: SamurAI system architecture, with Always-Responsive and On-Demand sub-systems and associated power domains.

\begin{tabular}{|c|c|c|c|c|c|c|c|c|}
\hline & \multicolumn{3}{|c|}{ Always-Responsive (AR) } & \multicolumn{2}{c|}{ TP-SRAM } & \multicolumn{3}{c|}{ On-Demand (OD) } \\
\hline Power mode & $\begin{array}{c}\text { Voltage } \\
\text { (V) }\end{array}$ & $\begin{array}{c}\text { Wuc } \\
\text { state }\end{array}$ & $\begin{array}{c}\text { WuR } \\
\text { State }\end{array}$ & $\begin{array}{c}\text { Voltage } \\
\text { (V) }\end{array}$ & State & $\begin{array}{c}\text { Voltage } \\
\text { (V) }\end{array}$ & $\begin{array}{c}\text { RISC-V } \\
\text { Freq (MHz) }\end{array}$ & $\begin{array}{c}\text { Periph } \\
\text { Freq (MHz) }\end{array}$ \\
\hline IDLE & 0.45 & Sleep & OFF & 0.48 & Sleep & OFF & - & - \\
\hline WuC only & 0.45 & Run & OFF & 0.48 & Run & OFF & - & - \\
\hline WuC+WuR & 0.45 & Run & ON & 0.48 & Run & OFF & - & - \\
\hline $\begin{array}{c}\text { WuC+Periph. } \\
\text { (cpu sleep) }\end{array}$ & 0.45 & Run & ON/OFF & 0.48 & Run & 0.48 & Gated & 10 \\
\hline CPU running & 0.45 & Run/Sleep & ON/OFF & $0.48-0.9$ & Run & $0.48-0.9$ & $1-350$ & $1-350$ \\
\hline
\end{tabular}

Fig. 2: SamurAI power modes.
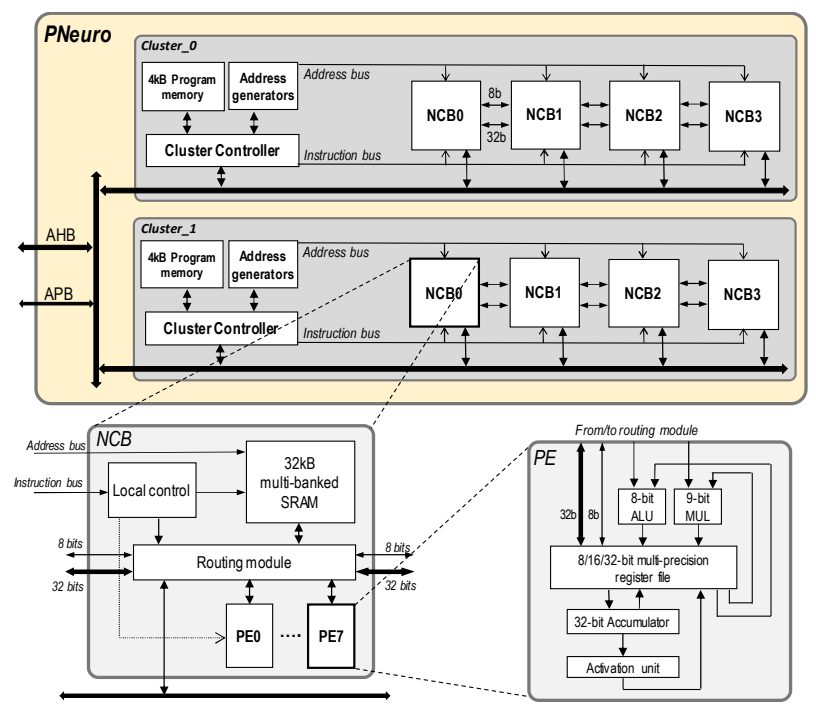

Fig. 4: Two-cluster PNeuro accelerator with 64 PEs.
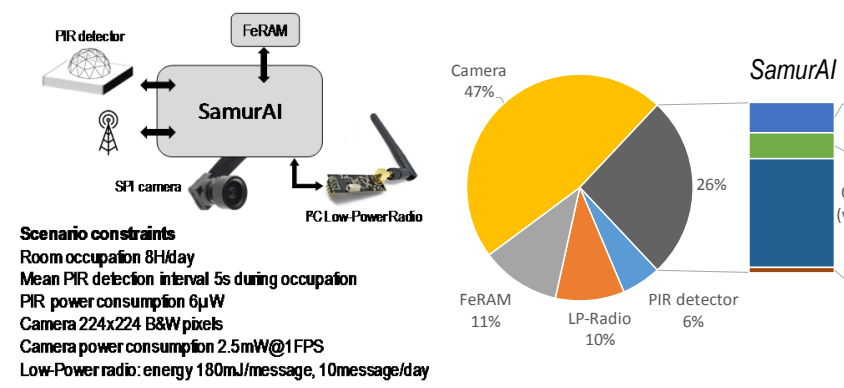

Fig. 9: Presence classification Fig. 10: Daily average power breakdown scenario using SamurAI with of presence classification scenario off-the-shelf components.

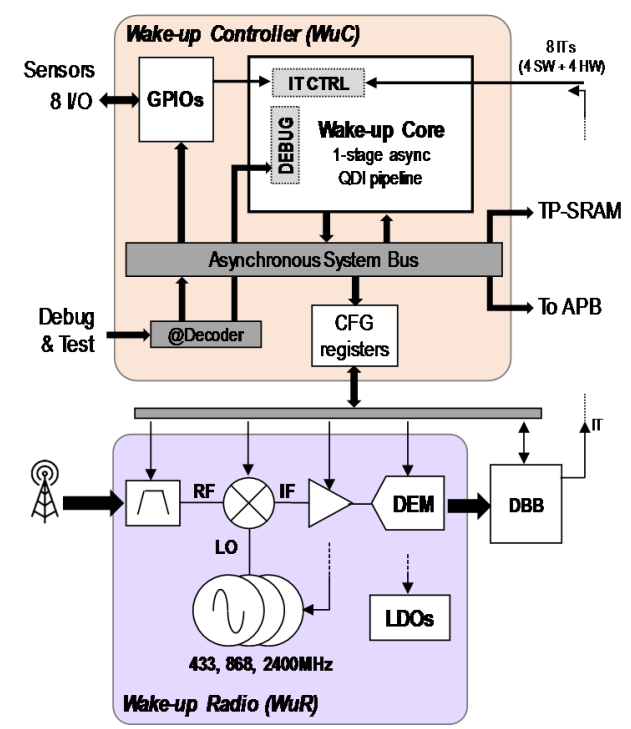

Fig. 3: Wake-up Controller and Radio architecture details.

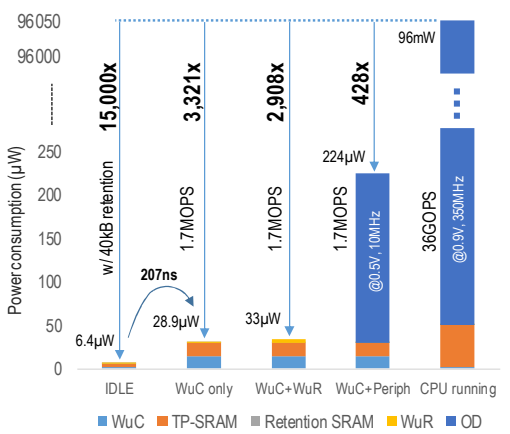

Fig. 5: Power consumption measurements and reduction w.r.t. power modes.

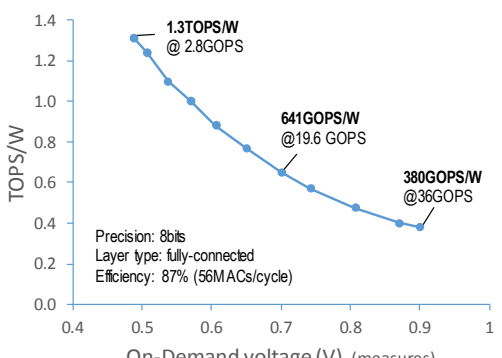

On-Demand voltage $(\mathrm{V})$ (measures)

Fig. 7: PNeuro energy efficiency.

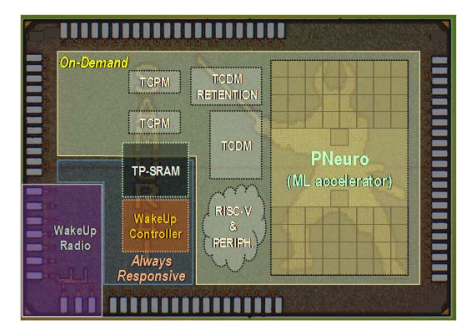

Fig. 8: Die micrograph, $4.5 \mathrm{~mm}^{2}$.

\begin{tabular}{|c|c|c|c|c|c|c|c|}
\hline & This work & $\begin{array}{c}\text { JSSC 2018 J J } \\
\text { Lallement [1] }\end{array}$ & $\begin{array}{l}\text { JSSC 2018 } \\
\text { Yu Pu [2] }\end{array}$ & $\begin{array}{l}\text { JSSC 2017 } \\
\text { S. Paul [3] }\end{array}$ & $\begin{array}{l}\text { JSSCC 2016 } \\
\text { J. Myers [4] }\end{array}$ & $\begin{array}{l}\text { ISSCC 2017 } \\
\text { S. Bang [5] }\end{array}$ & $\begin{array}{c}\text { JSSC 2019 } \\
\text { A. Pullini [6] }\end{array}$ \\
\hline Technology & $28 \mathrm{~nm}$ FDSOI & 28nm FDSOI & $28 \mathrm{~nm} \mathrm{LP}$ & $14 \mathrm{~nm}$ FinfET & $65 \mathrm{~nm} L P$ & $40 \mathrm{~nm}$ & $40 \mathrm{~nm}$ LP \\
\hline CPU & $\begin{array}{l}\text { 32b Async } \\
32 \mathrm{~b} \text { RISC }\end{array}$ & $\mathrm{MO}+$ & Mo & $\times 86 / A$ & $\mathrm{MO}+$ & Mo & $\begin{array}{c}32 \mathrm{~b} \\
\text { RCVC32IMFX }\end{array}$ \\
\hline Memory & 464kB SRAM & 8kB SRAM & - & \begin{tabular}{|c|}
$72 \mathrm{kB} \mathrm{SRAM}$ \\
$8 \mathrm{kB} / \mathrm{S}$ \\
$16 \mathrm{kB}$ ROM
\end{tabular} & 24kB SRAM & 270kB SRAM & $\begin{array}{c}512 \mathrm{kB} \mathrm{SRAM} \\
4 \mathrm{kB} \$ 64 \mathrm{kB} D\end{array}$ \\
\hline Wake-up Radio & Yes & No & No & No & No & No & No \\
\hline ML accelerator & Yes & No & Yes & No & No & Yes & Yes \\
\hline AVS & Yes & No & Yes & Yes & Yes & No & Yes \\
\hline Crypto IPs & Yes & No & No & No & Yes & No & No \\
\hline $\begin{array}{l}\text { CPU state retention } \\
\text { in deep sleep }\end{array}$ & Yes & No & - & Yes (S1) & Yes & No & Yes \\
\hline Voltage range & $0.45 \mathrm{~V}-0.9 \mathrm{~V}$ & $0.47 \mathrm{~V}-0.65 \mathrm{~V}$ & 0.55 & $0.308 \mathrm{~V}-1 \mathrm{~V}$ & $0.25 \mathrm{~V}-1.2 \mathrm{~V}$ & $0.63 \mathrm{~V}-0.9 \mathrm{~V}$ & $0.8 \mathrm{~V}-1.1 \mathrm{~V}$ \\
\hline Maximum frequency & $350 \mathrm{MHz}$ & $150 \mathrm{MHz}$ & $50 \mathrm{MHz}$ & $297 \mathrm{MHz}$ & $66 \mathrm{MHz}$ & $19.3 \mathrm{MHz}$ & $450 \mathrm{MHz}$ \\
\hline $\begin{array}{l}\text { Deep sleep power } \\
\text { (retention memory) }\end{array}$ & $\begin{array}{c}6.4 \mu \mathrm{W} \\
\text { (40kB SRAM) }\end{array}$ & $\begin{array}{c}0.704 \mu \mathrm{W} \\
\text { (8kB SRAM) }\end{array}$ & $\begin{array}{c}1.71 \mu \mathrm{W} \\
(\mathrm{NA})\end{array}$ & - & $\begin{array}{c}\text { 80nW } \\
\text { (8kB SRAM) }\end{array}$ & - & $\begin{array}{c}108 \mu \mathrm{W} \\
\text { (448kB SRAM) }\end{array}$ \\
\hline $\begin{array}{l}\text { Peak-to-idle power } \\
\text { reduction }\end{array}$ & $15,000 x$ & $51.5 x$ & - & $4.7 x$ & $6,940 x$ & - & $1,416 \mathrm{x}$ \\
\hline $\begin{array}{l}\text { Wake-up time from } \\
\text { deep-sleep }\end{array}$ & $\begin{array}{c}\text { 207ns } \\
\text { (35\% of inst. cycle) }\end{array}$ & $\sim \mu \mathrm{s}$ & - & $\begin{array}{l}>1 \mathrm{~ms}(\mathrm{~S} 1) \\
>1 \mathrm{~s}(\mathrm{SO})\end{array}$ & $\sim \mu \mathrm{s}$ & - & - \\
\hline GOPS & 1.7MOPS-36GOPS & 150MOPS & . & . & $66 \mathrm{MOPS}$ & - & 7GOPS \\
\hline Best performance & $\begin{array}{l}1.3 \mathrm{TOPS} / \mathrm{W} \\
@ 2.8 \mathrm{GOPS}\end{array}$ & $\begin{array}{c}\text { 370GOPS/W } \\
\text { @ 16MOPS }\end{array}$ & - & $\begin{array}{l}\text { 58GOPS/W } \\
\text { @ 3.5MOPS }\end{array}$ & $\begin{array}{l}\text { 85GOPS/W } \\
\text { @ 750kOPS }\end{array}$ & $\begin{array}{l}\text { 374GOPS/W } \\
@ 107 \mathrm{MOPS}\end{array}$ & $\begin{array}{c}\text { 120GOPS/W } \\
@ 2.2 \mathrm{GOPS}\end{array}$ \\
\hline
\end{tabular}

Fig. 11: Comparison table. 